DOI 10. 18307/2020. 0312

(c) 2020 by Journal of Lake Sciences

\title{
西洞庭湖季节性淹水和植被类型对温室气体排放通量的影响"
}

\author{
郭 佳 ${ }^{1}$, 晁碧霄 ${ }^{1},{\text { 张 } \text { 颖 }^{2} \text {, 雷光春 }}^{1}$, 王玉王 ${ }^{1 * *}$ \\ (1: 北京林业大学生态与自然保护学院, 北京 100083) \\ (2: 中国农业大学资源与环境学院, 北京 100094)
}

\begin{abstract}
摘 要: 植被类型及淹水带来的干湿交替过程是影响温室气体排放的重要因素. 本文通过原状土柱模拟实验,模拟西洞 庭湖水文节律变化对不同土壤一植被系统温室气体排放的影响. 利用静态箱一气相色谱法研究不同植被一土壤类型(芦苇 湿地、灰化苔草湿地和刚砍伐的杨树林湿地) 在季节性淹水条件下的 $\mathrm{CO}_{2} 、 \mathrm{CH}_{4}$ 和 $\mathrm{N}_{2} \mathrm{O}$ 的排放通量变化, 并探讨了在水位 变化的情况下, 不同植被一土壤类型对全球增温潜势的贡献. 结果表明:在不同的水文条件下, 芦苇湿地的 $\mathrm{CO}_{2}$ 排放通量 均显著高于苔草和杨树林湿地; 淹水过程导致 3 种植被类型覆盖湿地 $\mathrm{CO}_{2}$ 排放通量显著降低, 甲烷排放通量升高, 其中芦 苇湿地 $\mathrm{CH}_{4}$ 排放通量升高显著, 苔草和杨树林湿地 $\mathrm{CH}_{4}$ 排放通量升高不明显; 水文变化及植被类型对 $\mathrm{N}_{2} \mathrm{O}$ 排放通量的影 响不显著; 不同植被类型湿地对全球增温潜势的贡献为:芦苇>杨树林>苔草, 分别为 $16191.3 、 3405.6$ 和 $1883.1 \mathrm{~kg} / \mathrm{hm}{ }^{2}$. 本 研究结果表明在西洞庭湖湿地恢复过程中, 不再人为增大芦苇湿地面积, 将杨树林湿地恢复为苔草湿地, 更有利于降低 湿地恢复过程中温室气体的排放.
\end{abstract}

关键词: 温室气体; 干湿交替;植被类型;洞庭湖; 全球增温潜势

\section{Effects of seasonal flooding and vegetation types on greenhouse gas emission in west Lake Dongting*}

\author{
GUO Jia $^{1}$, CHAO Bixiao ${ }^{1}$, ZHANG Ying ${ }^{2}$, LEI Guangchun ${ }^{1} \&$ WANG Yuyu ${ }^{1 * *}$ \\ (1: School of Ecology Nature Conservation, Beijing Forestry University, Beijing 100083, P.R.China) \\ (2: College of Resources and Environmental Sciences, China Agricultural University, Beijing 100094, P.R.China)
}

\begin{abstract}
Seasonal flooding and vegetation types are the main drivers of greenhouse gases fluxes in wetland ecosystems. In this study, undisturbed soil column simulation experiments were carried out to study the effects of hydrological regime on the emission of greenhouse gases from wetlands dominated by different types of vegetation in west Lake Dongting. Three types of vegetation were tested, i.e. Phragmites australis, Carex cinerascens and Populus deltoides. Static opaque chamber/gas chromatography method was used to measure the flux of $\mathrm{CO}_{2}, \mathrm{CH}_{4}$ and $\mathrm{N}_{2} \mathrm{O}$ from wetlands with different vegetation types under the same dry-wet treatment. The results showed that the contributions of wetland to global warming potential were $16191.3,3405.6$ and $1883.1 \mathrm{~kg} / \mathrm{ha}{ }^{2}$ for wetlands dominated by $P$. australis, $P$. deltoides and C. cinerascens, respectively. Specifically, $\mathrm{CO}_{2}$ flux from $P$. australis wetland was significantly higher than that from $C$. cinerascens and $P$. deltoides wetlands, and flooding resulted in a significant decrease in $\mathrm{CO}_{2}$ emis- $^{-}$ sion regardless of vegetation type. Flooding significantly increased methane emission from $P$. australis wetland but the increase was not significant for $C$. cinerascens and $P$. deltoides wetlands. For $\mathrm{N}_{2} \mathrm{O}$ emission, the effects of both flooding and vegetation types were not significant. The results of this study indicate that the current wetland restoration program in west Lake Dongting, such as curbing the expanding of $P$. australis and converting $P$. deltoides wetland to $C$. cinerascens wetland, could potentially reduce its contribution to global warming.
\end{abstract}

Keywords: Greenhouse gases; dry and wet alternation; vegetation type; Lake Dongting; global warming potential

\footnotetext{
* 2019-07-01 收稿;2019-10-12 收修改稿.

国家自然科学基金项目 (41503077) 和国家重点研发计划项目 (2017YFC0405303) 联合资助.

** 通信作者;E-mail: wangyy@ bjfu.edu.cn.
} 
由温室气体引起的全球变暖目前仍是各国政府和科学家关注的重点, $\mathrm{CO}_{2} 、 \mathrm{CH}_{4}$ 和 $\mathrm{N}_{2} \mathrm{O}$ 是影响全球变暖 的关键温室气体 ${ }^{[1]}$. 近 100 年内 $\mathrm{CH}_{4}$ 的全球增温潜势 $(G W P)$ 大约是 $\mathrm{CO}_{2}$ 的 28 倍, 而 $\mathrm{N}_{2} \mathrm{O}$ 的 GWP 大约是 $\mathrm{CO}_{2}$ 的 265 倍. 近年来研究表明这 3 种温室气体对全球气候变暖的贡献率已经超过了 $90 \%{ }^{[2]}$. 湿地不仅是陆地 上巨大的有机碳储库, 同时, 严格的厌氧环境、巨大的物质与能量循环, 使湿地排放大量的 $\mathrm{CH}_{4}$ 和 $\mathrm{N}_{2} \mathrm{O}$ 等温 室气体 ${ }^{[3]}$, 其中 $\mathrm{CH}_{4}$ 排放量占全球排放总量的 $20 \% \sim 39 \%, \mathrm{CO}_{2}$ 排放量占全球排放总量的 5\% 8\% ${ }^{[4]}$.

已有研究表明,湿地内生长的植被对温室气体的产生、消耗和传输过程有重要影响 ${ }^{[4-5]}$ :一方面, 植被根 系及枯落物的存在为微生物的附着和活动提供了环境和有机物 ${ }^{[6]}$, 促进了细菌群落组成的多样性, 改变了 土壤碳含量和 $\mathrm{pH}$ 值 ${ }^{[7]}$, 从而对温室气体的产生造成影响; 另一方面, 不同的湿地类型植被, 解剖结构和生理 学特征各异, 对温室气体的运输能力不同 ${ }^{[8]}$. 维管束植物的通气组织向根部运输氧气以维持根的呼吸作用, 同时也是植物传输温室气体, 特别是 $\mathrm{CH}_{4}$ 的主要通道 ${ }^{[9]}$. 此外, 植被类型及植物的生长状况都会对湿地生态 系统温室气体的排放产生重要影响 ${ }^{[10]}$ : 印杰等通过实验研究揭示了有植物群落存在的沉积物中 $\mathrm{CO}_{2}$ 的累积 排放量显著高于无植物群落存在的光滩 ${ }^{[11]}$; 李杨杰通过植被对长江口温室气体排放影响机制的研究表明, 不同植被类型在不同的生长阶段对温室气体的源汇功能不一致,长江口海三棱蔗草、芦苇以及互花米草这 3 种主要植被在 $\mathrm{CH}_{4}$ 的排放过程中均起着重要的促进作用; 在 $\mathrm{CO}_{2}$ 的排放中, 芦苇表现为汇, 海三棱蔍草未萌 发时表现为源, 萌发后表现为汇, 等到调亡后再次表现为源 ${ }^{[5]}$. 湿地植被对于 $\mathrm{N}_{2} \mathrm{O}$ 的运输和排放过程同样起 着关键作用, 植物根系可以吸收其周围的 $\mathrm{N}_{2} \mathrm{O}$ 并向上运输 ${ }^{[12]}$, 最终通过叶片上的气孔将 $\mathrm{N}_{2} \mathrm{O}$ 排到空 气中 ${ }^{[13]}$.

水文条件作为湿地重要的生态属性,水位波动会对湿地大气一植被一土壤之间碳的生物地球化学过程 中各环节的方向与强度造成影响 ${ }^{[14]}$. 厌氧环境和有氧环境的转变, 使得温室气体的排放量及 3 种温室气体 比例发生较大的变化. 许多研究表明, 干燥一再湿润循环强烈影响着土壤的碳氮循环过程 ${ }^{[15]}$, 微生物的生物 量及其活动 ${ }^{[16]}$, 以及 $\mathrm{CO}_{2} 、 \mathrm{CH}_{4}$ 和 $\mathrm{N}_{2} \mathrm{O}$ 等温室气体的排放 ${ }^{[17]}$. Altor 等研究表明, 与永久性淹没的地区相比, 水位波动使得土壤间歇性暴露在大气中的区域, $\mathrm{CH}_{4}$ 的排放量显著增高 ${ }^{[18]}$; Mander 等研究发现, 在低水位 时, $\mathrm{CO}_{2}$ 和 $\mathrm{N}_{2} \mathrm{O}$ 的排放量更高, 而在高水位时, $\mathrm{CH}_{4}$ 的排放量更高 ${ }^{[19]}$. 水位降低到一定程度, 湿地会从 $\mathrm{CH}_{4}$ 的 释放源转变为 $\mathrm{CH}_{4}$ 的吸收汇, 一定范围内的水位下降会导致 $\mathrm{N}_{2} \mathrm{O}$ 排放量增加, 而当水位进一步下降时, $\mathrm{N}_{2} \mathrm{O}$ 排放量将减少 ${ }^{[20]}$. 但已有的研究多集中在陆地及滨海地区, 而对于长江流域通江湖泊的研究较少.

洞庭湖是我国的第二大淡水湖, 也是长江中游仅存的两个通江湖泊之一 ${ }^{[21]}$, 受自然地理条件、气候条 件、江湖关系变化等因素的影响,其水位及消落带面积呈现出周期性变化 ${ }^{[22]}$. 一般 4-9 月是丰水期,湖水水 位偏高,其中 7-8 月呈现高水位; 10 月至翌年 3 月为枯水期,水位较低. 史璇研究发现洞庭湖 1961-2008 年间, 湖滨消落带面积在 $1336 \sim 2920 \mathrm{~km}^{2}$ 之间波动, 多年平均消落带面积为 $2434.5 \mathrm{~km}^{2[23]}$. 西洞庭湖湿地位 于洞庭湖西部, 湿地内不仅分布着芦苇、苔草等典型湿地植被, 还分布有杨树人工林. 在 $1990 \mathrm{~s}$ 末期, 为了经 济利益通过挖沟抬垄在西洞庭湖种植了大量的杨树林, 造成了湿地面积萎缩、水鸟栖息地减少等一系列生 态问题. 2013 年起西洞庭湖开展 “退林还湿”工程, 开始大量砍伐杨树林并进行湿地生态修复 ${ }^{[24]}$, 目前, 西洞 庭湖国家级自然保护区核心区范围内的杨树林已经基本被移除, 缓冲区和实验区的杨树林清除工作仍在进 行. 近年来由于三峡水库蓄水以及气候变化等原因, 西洞庭湖水文条件发生了一定程度上的改变. 综上所 述, 在进行湿地恢复的过程中研究西洞庭湖湿地在水文条件变化条件下温室气体排放通量的规律, 对于西 洞庭湖湿地恢复特别是植被恢复具有重要意义.

\section{1 研究区概况与研究方法}

\section{1 研究区概况}

实验地点位于湖南省汉寿县西洞庭湖国家级自然保护区, 属于中亚热带季风气候, 气候温和, 日照充 足, 雨量充沛, 年均气温 $16.7^{\circ} \mathrm{C}$, 降水量 $1200 \sim 1350 \mathrm{~mm}$, 无霜期 274 天. 保护区内主要分布有禾本科、莎草科 等多种植物群落. 除此之外, 由于人为影响, 西洞庭湖国家级自然保护区内曾分布有杨树人工林. 截至目前, 核心区内的杨树人工林已经被全部移除,正处于湿地恢复阶段. 


\section{2 研究方法}

1.2 .1 野外样品采集 通过前期文献阅读和实地考察, 选取了芦苇 $\left(28^{\circ} 51^{\prime} 07.64^{\prime \prime} \mathrm{N}, 112^{\circ} 12^{\prime} 44.92^{\prime \prime} \mathrm{E}\right)$ 、苔草 $\left(28^{\circ} 51^{\prime} 22.04^{\prime \prime} \mathrm{N}, 112^{\circ} 13^{\prime} 50.26^{\prime \prime} \mathrm{E}\right) 、$ 、刚砍伐的杨树林 $\left(28^{\circ} 55^{\prime} 19.37^{\prime \prime} \mathrm{N}, 112^{\circ} 11^{\prime} 58.75^{\prime \prime} \mathrm{E}\right) 3$ 个样点. 2018 年 1 月, 在以样点为中心的群落内, 随机选择 3 个点, 分别采集 $0 \sim 10 、 10 \sim 20 、 20 \sim 30 \mathrm{~cm}$ 的沉积物样品, 装人自封袋 里保存, 带回实验室分析其理化性质. 用直径为 $31.5 \mathrm{~cm}$, 高为 $30 \mathrm{~cm}$ 的 PVC 管, 在每种植被类型的样地上各 取 16 个原状土带回实验站用于模拟实验.

1.2.2 实验设计 将采回的原状土柱静置至植被萌发, 其中芦苇样点取回的土柱主要萌发的植被为芦苇 (Phragmites australis), 苔草和杨树林样点取回的土柱主要萌发的植被为莎草科的灰化苔草 (Carex cinerascens) (在后文描述中简称为芦苇湿地、苔草湿地和杨树林湿地), 每种植被类型中选取生物量相近的 3 个原状土柱进行试验, 每组 3 个重复. 将原状土柱上接 $0.5 \mathrm{~m}$ 的 PVC 管后, 按照洞庭湖水文变化节律进行 淹水 (7月 5 日) 和退水 (10 月 1 日) 处理. 淹水高度设置为 $0.4 \mathrm{~m}$, 淹水时, 苔草平均高度约 $0.6 \mathrm{~m}$, 芦苇平均 高度约为 $1.1 \mathrm{~m} .2018$ 年 5 月- 2019 年 1 月对原状土柱温室气体排放通量进行监测, 频率为 1 次/月, $4 \sim 7$ 天/次.

1.2 .3 气体采集及分析 温室气体监测采用静态暗箱一气相色谱法. 为了方便淹水和采样, 在淹水前将原状 土柱上接 $0.5 \mathrm{~m} \mathrm{PVC}$ 材质的延长箱, 淹水高度为 $0.4 \mathrm{~m}$, 留下高度为 $0.1 \mathrm{~m}$ 的气室用于采集气体样品. 每次采 样前盖上 PVC 材质的盖子, 并用封口膜密封; 盖子内部装有一个小风扇, 保证在采样时, 箱内气体混合均匀; 并且盖子上装有橡胶管连接的出气口. 采集气体样品时, 用带有三通阀的医用 $100 \mathrm{~mL}$ 注射器连接采样箱出 气口和气袋, 把盖子盖上后立刻采集第一袋气体样品, 取箱内气体后把气体样品注人到容积为 $100 \mathrm{~mL}$ 的气 袋中储存. 之后每隔 $10 \mathrm{~min}$ 完成一袋气体样品的采样, 每个采样点共采集 4 袋气体样品, 运到实验室进行分 析. 采集样品的同时,记录箱内温度. 采样后,记录每个采样箱的气室高度,用于温室气体排放通量的计算.

\section{3 数据计算及统计分析}

1.3.1 数据计算 采用公式(1) 计算温室气体排放通量:

$$
F=\frac{M}{V_{0}} \cdot \frac{P}{P_{0}} \cdot \frac{T_{0}}{T} \cdot \frac{\mathrm{d} C_{t}}{\mathrm{~d} t} \cdot H
$$

式中, $F$ 为温室气体 $\left(\mathrm{CO}_{2} 、 \mathrm{CH}_{4}\right.$ 和 $\left.\mathrm{N}_{2} \mathrm{O}\right)$ 排放通量 $\left(\mathrm{mg} /\left(\mathrm{m}^{2} \cdot \mathrm{h}\right)\right), M$ 为气体摩尔质量 $(\mathrm{g} / \mathrm{mol}), V_{0}$ 为标准状态 下气体的摩尔体积 $\left(V_{0}=22.4 \mathrm{~L} / \mathrm{mol}\right), P$ 为采样时刻大气压 $(\mathrm{kPa}), P_{0}$ 为标准大气压 $\left(P_{0}=101.325 \mathrm{kPa}\right), T_{0}$ 为 标准状态下的绝对温度 $\left(T_{0}=237.15 \mathrm{~K}\right), T$ 为采样时刻温度 $(\mathrm{K}), \mathrm{d} C_{t} / \mathrm{d} t$ 为箱内气体浓度变化速率, $H$ 为气室 高度 $(\mathrm{m})$.

采用公式(2)计算气体累积排放量:

$$
C E=\sum_{i}^{n} \frac{F_{i}+F_{i+1}}{2}\left(t_{i+1}-t_{i}\right) \times 24
$$

式中, $C E$ ( cumulative emission) 表示温室气体 $\left(\mathrm{CO}_{2} 、 \mathrm{CH}_{4}\right.$ 和 $\left.\mathrm{N}_{2} \mathrm{O}\right)$ 的累积排放量 $\left(\mathrm{g} / \mathrm{m}^{2}\right) ; F$ 为温室气体排放通 量 $\left(\mathrm{mg} /\left(\mathrm{m}^{2} \cdot \mathrm{h}\right)\right) ; i$ 表示第 $i$ 次气体采样; $t_{i+1}-t_{i}$ 表示两个相邻测定日期的间隔 $(\mathrm{d}) ; n$ 为通量观测次数.

采用公式 $(3)$ 计算综合增温潜势:

$$
G W P=C E_{\mathrm{CO}_{2}}+28 C E_{\mathrm{CH}_{4}}+265 C E_{\mathrm{N}_{2} \mathrm{O}}
$$

式中, $G W P$ 为全球增温潜势 $\left(\mathrm{kg} / \mathrm{hm}^{2}\right)$. IPCC 指出最近 100 年的时间尺度内, 同质量的 $\mathrm{CH}_{4}$ 和 $\mathrm{N}_{2} \mathrm{O}$ 的增温效 应分别是 $\mathrm{CO}_{2}$ 的 28 倍和 265 倍( IPCC, 2013).

1.3.2 数据分析 本研究数据使用 IBM SPSS Statistics 23 进行单因素方差分析 ANOVA,采用林肯检验比较不 同淹水时期 ${ }^{[25]}$ 、不同植被类型下温室气体排放通量的差异,采用 SigmaPlot 12.5 软件完成绘图.

\section{2 结果分析}

\section{1 不同植被类型湿地沉积物中主要环境因子}

从表 1 可以看出, $0 \sim 10 \mathrm{~cm}$ 和 $10 \sim 20 \mathrm{~cm}$ 的土壤含水率排序为: 苔草>芦苇>杨树林, 苔草湿地含水率显 著高于芦苇和杨树林湿地 $(P<0.05) ; 20 \sim 30 \mathrm{~cm}$ 的土壤含水率无显著差异 $(P>0.05)$. 无论哪个土层, 杨树林 
湿地的土壤含水率均为最低. $0 \sim 10 \mathrm{~cm}$ 土层中, 杨树林湿地土壤中全氮含量显著高于芦苇和苔草湿地 $(P<$ $0.05), 20 \sim 30 \mathrm{~cm}$ 不同植被类型土层之间全氮含量差异不显著 $(P>0.05) .0 \sim 10 \mathrm{~cm}$ 的土层中, 杨树林的铵态 氮和有机碳含量均显著高于芦苇和苔草湿地 $(P<0.05)$, 在其他土层中差异不明显. 除此之外, 各个土层下不 同植被类型硝态氮含量差异不明显 $(P>0.05)$.

表 1 不同植被类型湿地土壤理化性质*

Tab.1 Main physical and chemical properties at different vegetation stages

\begin{tabular}{ccccccc}
\hline $\begin{array}{c}\text { 土层深度/ } \\
\mathrm{cm}\end{array}$ & 植被类型 & 含水率/\% & $\begin{array}{c}\text { 全氮/ } \\
(\mathrm{g} / \mathrm{kg})\end{array}$ & $\begin{array}{c}\text { 铵态氮/ } \\
(\mathrm{mg} / \mathrm{kg})\end{array}$ & $\begin{array}{c}\text { 硝态氮/ } \\
(\mathrm{mg} / \mathrm{kg})\end{array}$ & $\begin{array}{c}\text { 有机碳/ } \\
(\mathrm{g} / \mathrm{kg})\end{array}$ \\
\hline \multirow{2}{*}{$0 \sim 10$} & 杨树林 & $22.31 \pm 0.63^{\mathrm{a}}$ & $1.63 \pm 0.03^{\mathrm{a}}$ & $4.81 \pm 0.74^{\mathrm{a}}$ & $5.40 \pm 0.60^{\mathrm{a}}$ & $22.85 \pm 1.65^{\mathrm{a}}$ \\
& 芦苇 & $24.14 \pm 0.26^{\mathrm{a}}$ & $1.41 \pm 0.07^{\mathrm{b}}$ & $3.62 \pm 0.21^{\mathrm{ab}}$ & $8.41 \pm 0.79^{\mathrm{a}}$ & $19.93 \pm 3.15^{\mathrm{ab}}$ \\
& 苔草 & $26.92 \pm 0.32^{\mathrm{b}}$ & $1.09 \pm 0.02^{\mathrm{b}}$ & $2.84 \pm 0.32^{\mathrm{b}}$ & $2.87 \pm 0.26^{\mathrm{a}}$ & $14.49 \pm 3.55^{\mathrm{b}}$ \\
\multirow{2}{*}{$10 \sim 20$} & 杨树林 & $20.66 \pm 0.33^{\mathrm{a}}$ & $1.26 \pm 0.02^{\mathrm{a}}$ & $2.94 \pm 0.50^{\mathrm{a}}$ & $3.00 \pm 0.52^{\mathrm{a}}$ & $17.15 \pm 0.62^{\mathrm{a}}$ \\
& 芦苇 & $25.19 \pm 1.11^{\mathrm{ab}}$ & $1.31 \pm 0.03^{\mathrm{a}}$ & $2.12 \pm 0.16^{\mathrm{a}}$ & $4.28 \pm 0.47^{\mathrm{a}}$ & $16.37 \pm 2.41^{\mathrm{ab}}$ \\
& 苔草 & $27.03 \pm 3.07^{\mathrm{b}}$ & $1.22 \pm 0.07^{\mathrm{a}}$ & $2.74 \pm 0.24^{\mathrm{a}}$ & $2.79 \pm 0.75^{\mathrm{a}}$ & $20.62 \pm 1.54^{\mathrm{b}}$ \\
& 杨树林 & $20.77 \pm 0.06^{\mathrm{a}}$ & $1.18 \pm 0.02^{\mathrm{a}}$ & $2.26 \pm 0.23^{\mathrm{a}}$ & $2.71 \pm 0.22^{\mathrm{a}}$ & $16.66 \pm 0.16^{\mathrm{a}}$ \\
& 芦苇 & $23.17 \pm 0.38^{\mathrm{a}}$ & $1.21 \pm 0.04^{\mathrm{a}}$ & $2.32 \pm 0.38^{\mathrm{a}}$ & $3.32 \pm 0.21^{\mathrm{a}}$ & $15.86 \pm 1.16^{\mathrm{a}}$ \\
& 苔草 & $22.74 \pm 0.33^{\mathrm{a}}$ & $0.90 \pm 0.06^{\mathrm{a}}$ & $2.63 \pm 0.37^{\mathrm{a}}$ & $2.08 \pm 0.11^{\mathrm{a}}$ & $14.48 \pm 4.11^{\mathrm{a}}$ \\
\hline
\end{tabular}

* 数据为平均值和标准误. 分别对 3 组数据 $(0 \sim 10 、 10 \sim 20 、 20 \sim 30)$ 各项指标进行了多重比较, 标记相同字母表示该组数 据无显著性差异,标注不同字母则表示有显著性差异 $(P<0.05)$.

\section{2 温室气体排放通量年内变化趋势}

各个植被类型 3 种温室气体 $\left(\mathrm{CO}_{2} 、 \mathrm{CH}_{4}\right.$ 和 $\left.\mathrm{N}_{2} \mathrm{O}\right)$ 排放通量在淹水条件发生改变后, 表现出基本一致的变 化趋势. 对于 $\mathrm{CO}_{2}$ 而言, 在 7 月淹水后其在 3 种植被一土壤类型下的排放通量均明显降低 (图 1a), 在淹水期 间, $8 、 9$ 月,芦苇植被一土壤体系的 $\mathrm{CO}_{2}$ 排放通量有所上升, 苔草和杨树林植被一土壤体系的 $\mathrm{CO}_{2}$ 排放通量波 动不大; 对于 $\mathrm{CH}_{4}$ 而言, 在 7 月淹水后其在芦苇和杨树林植被一土壤体系的排放通量均明显增加 (图 $1 \mathrm{~b}$ ), 在 9 月达到最大值, 芦苇湿地为 $144.59 \mathrm{mg} /\left(\mathrm{m}^{2} \cdot \mathrm{h}\right)$, 杨树林湿地为 $18.55 \mathrm{mg} /\left(\mathrm{m}^{2} \cdot \mathrm{h}\right)$, 而淹水后苔草湿地甲 烷的排放通量有所波动, 但变化趋势并不明显. 对于 $\mathrm{N}_{2} \mathrm{O}$ 而言, 淹水后, 在 3 种植被一土壤类型下的排放通 量稍有降低,但变化趋势并不明显 (图 1c). 在排水后, 3 种温室气体 $\left(\mathrm{CO}_{2} 、 \mathrm{CH}_{4}\right.$ 和 $\left.\mathrm{N}_{2} \mathrm{O}\right)$ 发生较大的波动. $\mathrm{CO}_{2}$ 和 $\mathrm{N}_{2} \mathrm{O}$ 的排放通量整体上呈现升高趋势, 个别监测日其排放通量有所降低; 芦苇湿地 $\mathrm{CH}_{4}$ 的排放通量明 显呈降低趋势, 而苔草和杨树林湿地 $\mathrm{CH}_{4}$ 的排放通量波动较大.

\section{3 季节性淹水对不同类型植被一土壤体系温室气体排放通量的影响}

将整个实验进程分为 3 个阶段, 即淹水前 (2018 年 5 月 6 日- 7 月 1 日)、淹水期 (2018 年 7 月 6 日 - 9 月 30 日) 和排水后 (2018 年 10 月 1 日-2019 年 1 月 9 日). 对不同植被类型在每个时期 3 种主要温室气体 $\left(\mathrm{CO}_{2} 、 \mathrm{CH}_{4}\right.$ 和 $\left.\mathrm{N}_{2} \mathrm{O}\right)$ 排放通量的平均值进行分析, 结果如图 2 所示. 水文条件及植被类型对 $\mathrm{CO}_{2}$ 和 $\mathrm{CH}_{4}$ 的排放 通量均有影响, 但对 $\mathrm{N}_{2} \mathrm{O}$ 的影响不显著 $(P>0.05)$.

对于 $\mathrm{CO}_{2}$ 而言 (图 2a), 在淹水前和淹水期内, 芦苇湿地的 $\mathrm{CO}_{2}$ 排放通量均明显高于苔草和杨树林湿地 $(P<0.05)$, 而苔草和杨树林湿地的 $\mathrm{CO}_{2}$ 排放通量无显著差异 $(P>0.05)$; 在排水后, 芦苇湿地和杨树林湿地的 $\mathrm{CO}_{2}$ 排放通量显著高于苔草湿地 $(P<0.05)$. 此外, 淹水过程对 $\mathrm{CO}_{2}$ 排放通量影响显著, 相比于淹水前, 淹水期 内芦苇、苔草、杨树林 3 种植被类型的 $\mathrm{CO}_{2}$ 排放通量均显著降低 $(P<0.05)$; 而退水过程对 $\mathrm{CO}_{2}$ 排放通量影响 并不显著,在排水后, 芦苇湿地 $\mathrm{CO}_{2}$ 排放通量稍有降低, 而苔草和杨树林湿地的 $\mathrm{CO}_{2}$ 排放通量有所增大.

对于 $\mathrm{CH}_{4}$ 而言 (图 2b), 在淹水前, 各个植被类型湿地的 $\mathrm{CH}_{4}$ 排放通量均处于较低的水平, 并无显著差异 $(P>0.05)$; 淹水期和排水后, 芦苇湿地 $\mathrm{CH}_{4}$ 的排放量均显著高于苔草和杨树林湿地的 $\mathrm{CH}_{4}$ 排放量 $(P<0.05)$. 淹 水过程对各植被类型 $\mathrm{CH}_{4}$ 排放通量均有影响, 淹水后 $\mathrm{CH}_{4}$ 排放通量升高, 排水后 $\mathrm{CH}_{4}$ 排放通量降低; 但淹水退 水对芦苇湿地 $\mathrm{CH}_{4}$ 的排放通量影响显著 $(P<0.05)$, 对苔草和杨树林湿地 $\mathrm{CH}_{4}$ 的排放通量影响并不显著 $(P>0.05)$. 

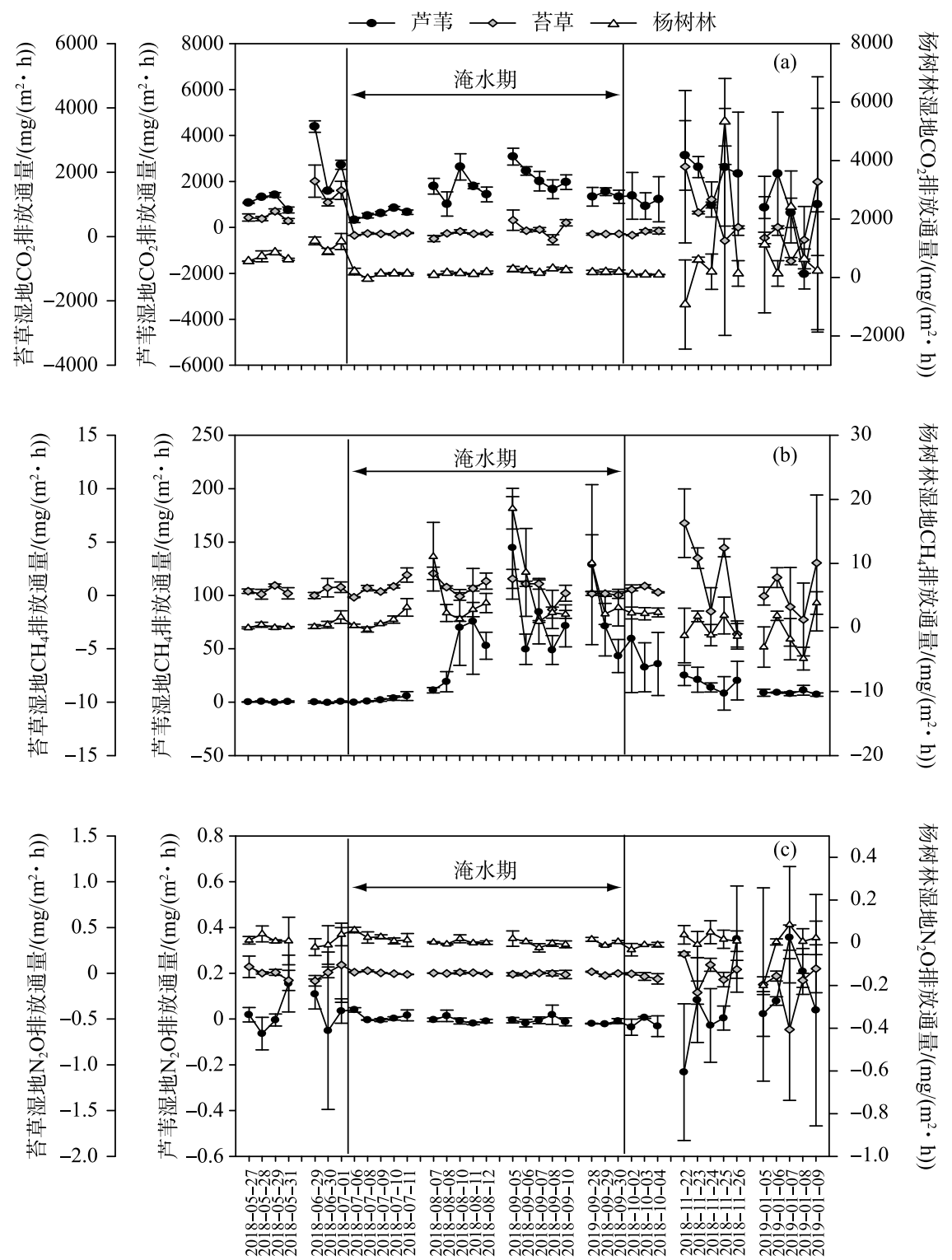

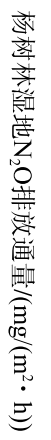

图 1 不同植被覆盖下主要温室气体排放通量的季节变化

Fig.1 The seasonal dynamics of main greenhouse gas fluxes under different vegetation covers

对于 $\mathrm{N}_{2} \mathrm{O}$ 而言 (图 2c), 其排放通量极小, 最大排放通量出现在排水后的芦苇湿地, 为 $0.06 \mathrm{mg} /\left(\mathrm{m}^{2} \cdot \mathrm{h}\right.$ ), 苔草湿地对于 $\mathrm{N}_{2} \mathrm{O}$ 表现为弱吸收, 芦苇和杨树林湿地对 $\mathrm{N}_{2} \mathrm{O}$ 表现为弱排放. 但各个水文时期和植被类型 下, $\mathrm{N}_{2} \mathrm{O}$ 的排放通量无显著差异 $(P>0.05)$.

\section{4 综合增温趋势}

不同植被类型湿地的 3 种温室气体对 GWP 的贡献表现出一致性 (图 3), 贡献程度为: $\mathrm{CO}_{2}>\mathrm{CH}_{4}>\mathrm{N}_{2} \mathrm{O}$. 整个观测期内, 芦苇、苔草、杨树林 3 种植被类型湿地中, GWP 分别为 $16191.3 、 3405.6$ 和 $1883.1 \mathrm{~kg} / \mathrm{hm}^{2}, \mathrm{CO}_{2}$ 对 GWP 的贡献率分别为: 66.99\%、101.16\% 和 83.29\%, $\mathrm{CH}_{4}$ 对 GWP 的贡献率分别为: $32.74 \% 、 4.32 \%$ 和 $17.08 \%, \mathrm{~N}_{2} \mathrm{O}$ 对 $G W P$ 的贡献率分别为: $0.27 \% 、-5.48 \%$ 和 $-0.37 \%$. 由此可以看出, 不同植被类型湿地主要通 
过增加 $\mathrm{CO}_{2}$ 的排放通量提高了其 GWP. 对于苔草和杨树 林湿地而言, 通过对 $\mathrm{N}_{2} \mathrm{O}$ 的吸收一定程度上削弱了苔草 和杨树林湿地的 GWP, 但由于 $\mathrm{N}_{2} \mathrm{O}$ 的排放通量极少, 影响 并不明显. 通过单因素方差分析 ANOVA 发现,芦苇湿地 对 GWP 的贡献显著大于苔草和杨树林湿地 $(P<0.05)$.

\section{3 讨论}

\section{1 水文过程及植被对温室气体的影响}

本研究发现水文过程和植被类型都会对 3 种主要温 室气体 $\left(\mathrm{CO}_{2} 、 \mathrm{CH}_{4}\right.$ 和 $\left.\mathrm{N}_{2} \mathrm{O}\right)$ 排放通量产生影响. 各植被类 型湿地在淹水后 $\mathrm{CO}_{2}$ 排放通量减少, 且芦苇湿地 $\mathrm{CO}_{2}$ 排放 通量显著高于苔草和杨树林湿地,这与盛宣才等的研究结 果基本一致 ${ }^{[26]}$. 由于淹水后,沉积物氧化还原环境发生了 改变 ${ }^{[27]}$, 氧浓度降低, 造成了 $\mathrm{CO}_{2}$ 排放通量降低. 以往研 究表明: 不同类型潮滩土壤呼吸之间的差异不大,植物地 上部分的呼吸是引起生态系统 $\mathrm{CO}_{2}$ 排放通量差异的主要 原因 ${ }^{[28-29]}$. 本研究采用的是静态一暗箱法, 测得的 $\mathrm{CO}_{2}$ 排 放通量主要包括土壤呼吸和植物暗呼吸两部分. 由于芦 苇地上生物量明显高于苔草和杨树林, 其通过暗呼吸所产 生的 $\mathrm{CO}_{2}$ 高于其余两种植被, 从而导致芦苇湿地 $\mathrm{CO}_{2}$ 排放 通量显著高于苔草和杨树林湿地. 而在淹水后芦苇湿地 $\mathrm{CO}_{2}$ 排放通量降低幅度小于苔草和杨树林湿地,其原因可 能是芦苇具有发达的通气组织, 可以向根系输送一定量的 氧气以改变区域的缺氧环境 ${ }^{[30]}$, 并且根部产生的 $\mathrm{CO}_{2}$ 可 以通过通气组织上传到空气中. 排水后, 芦苇湿地 $\mathrm{CO}_{2}$ 排 放通量比淹水期小, 这可能是由于排水后期到了秋冬季, 温度降低、芦苇开始枯萎死亡,许傘王豪等对苏北潮滩的 研究也表明 $\mathrm{CO}_{2}$ 的最低排放通量出现在冬季 ${ }^{[29]}$. 而苔草 和杨树林湿地在排水后温室气体排放通量升高,则可能是 由于氧化还原环境的瞬间改变提供了足够的氧气, 导致 $\mathrm{CO}_{2}$ 的排放量升高.

淹水期间,各植被类型的 $\mathrm{CH}_{4}$ 排放通量均有所增加, 该结果与前人的研究结果具有一致性 ${ }^{[31-32]}$. 可能是由于 淹水造成了严格的厌氧环境, 厌氧呼吸成为了绝大多数 湿地碳降解的主要途径, 最终产物一般为 $\mathrm{CH}_{4}{ }^{[33]}$. 此外, 很多研究表明植被种类对于 $\mathrm{CH}_{4}$ 排放通量有着重要的影 响 ${ }^{[5,34]}$. 本研究结果显示在淹水后芦苇湿地 $\mathrm{CH}_{4}$ 排放通 量增加显著 $(P<0.05)$, 苔草和杨树林湿地 $\mathrm{CH}_{4}$ 排放通量 也有所增加,但不显著. 该结果与他人的研究结果有所差 异, Ding 等 ${ }^{[35]}$ 和 Maucieri 等 ${ }^{[36]}$ 的研究均表明莎草科植物 对甲烷的传输能力大于禾本科. 虽然在本研究中苔草和 杨树林湿地中生长的植被主要为莎草科植物苔草和蔍 草, 芦苇湿地主要生长的植被为芦苇, 但芦苇湿地甲烷排 放通量在淹水后显著增高的可能原因如下: 在淹水 $0.4 \mathrm{~m}$
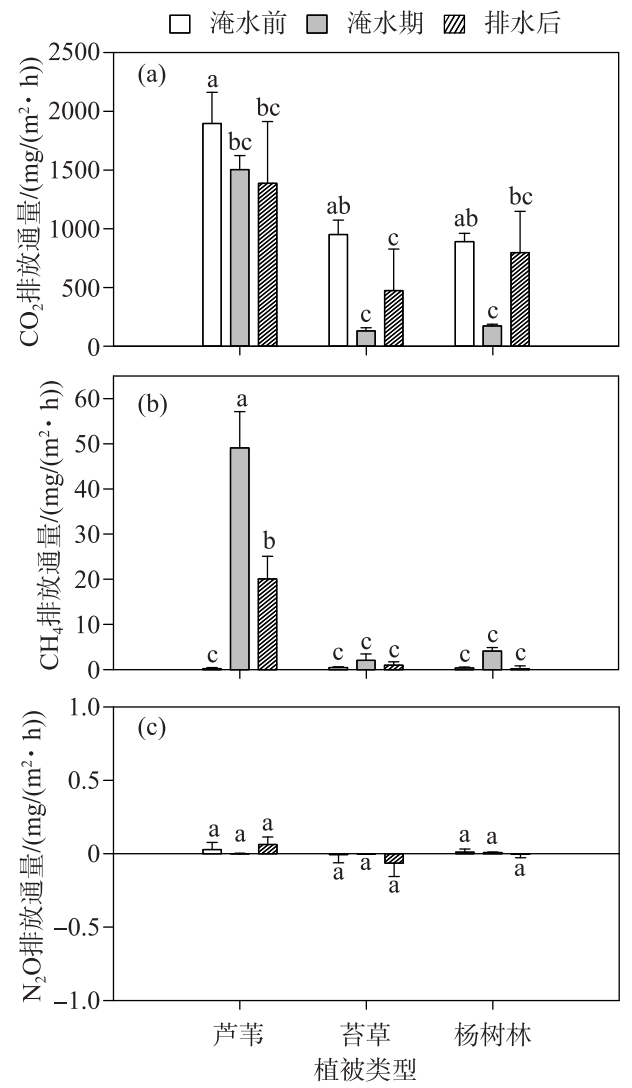

图 2 不同植被类型淹水和非淹水阶段 温室气体平均排放通量变化

(图中的数据为平均值和标准误, 方柱 标注不同字母则表示有显著性差异 $(P<0.05))$

Fig.2 The effect of flooding and non-flooding on main greenhouse gas fluxes under different vegetation covers

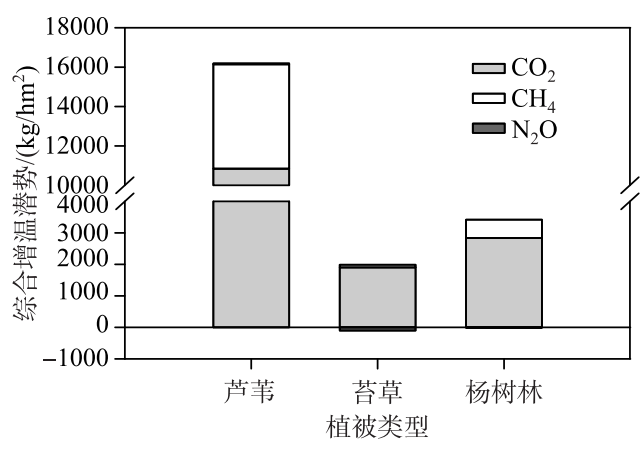

图 3 监测期间不同植被类型综合增温潜势

Fig.3 Global warming potential of different vegetation types during the monitoring period 
后苔草和杨树林湿地植被几乎被淹没到水面以下, 甚至一段时间后根部发生枯萎腐烂, 降低了其运输温室 气体的能力, 相对比而言, 芦苇作为挺水植物, 大部分茎叶仍处于水面之上, 发达的通气组织为运输 $\mathrm{CH}_{4}$ 提 供了通道. 排水后, 各个类型湿地的 $\mathrm{CH}_{4}$ 排放通量均有所降低. 这是由于在排水后, 环境由无氧状态变为有 氧状态, 氧化反应增强, 因此 $\mathrm{CH}_{4}$ 排放通量降低.

在整个监测期内,不同植被类型在不同水文条件下 $\mathrm{N}_{2} \mathrm{O}$ 的排放通量无显著差异 $(P>0.05)$. 多项研究表 明, $\mathrm{N}_{2} \mathrm{O}$ 的产生与土壤性质、含水率、电导率等环境因素及微生物种群等生物因子均存在密切关系 ${ }^{[37-38]}$, 但 $\mathrm{N}_{2} \mathrm{O}$ 的产生机制很复杂, 目前仍未得出统一结论. 但可以明确的是 $\mathrm{N}_{2} \mathrm{O}$ 主要来源于微生物参与下的硝化反 硝化反应, 土壤含水量低和土壤长期持续淹水都不利于硝化和反硝化细菌的生长 ${ }^{[33]}$; 也有研究表明植被类 型会对 $\mathrm{N}_{2} \mathrm{O}$ 的排放通量产生一定的影响 ${ }^{[39-40]}$.

\section{2 全球增温潜势}

本研究发现,不同植被类型湿地对于 GWP 的贡献不同,由大到小排序为:芦苇>杨树林>苔草. 许金金王豪 也曾通过研究指出, 植被对温室气体通量的排放起着至关重要的作用, 植被存在与否以及植被类型差异均 会影响温室气体排放, 进而导致 $G W P$ 存在一定的差异 ${ }^{[29]}$. Kandel 等在监测了干旱的河流再被重新淹水恢复 后的温室气体排放情况后发现, 在重新被淹水恢复的湿地中 $\mathrm{CO}_{2}$ 及 $\mathrm{N}_{2} \mathrm{O}$ 的排放通量较低, 但 $\mathrm{CH}_{4}$ 排放通量 持续处于较高水平 ${ }^{[41]}$. 西洞庭湖湿地自 2013 年开展了 “退林还湿”工程, 清除了保护区核心区内的杨树林, 开展湿地恢复, 其主要目的是恢复候鸟栖息地及恢复湿地生态功能. 湿地作为一个重要的碳库, 合理的恢复 及管理有望恢复天然湿地的碳汇功能, 因此在恢复过程中温室气体排放量的变化应该得到重视. 而本研究 结果, 在西洞庭湖目前的恢复阶段, 其碳汇功能可能尚未实现,但我们不难发现芦苇湿地的 GWP 明显高于 其余两种植被类型, 因此我们建议, 在可能的情况下, 不再人为地种植芦苇, 尽可能地将杨树林恢复为苔草 湿地,更有利于减少温室效应.

\section{4 参考文献}

[ 1 ] Alexander L, Allen S, Bindoff NL. Climate change 2013: The physical science basis-summary for policymakers. Intergovernmental Panel on Climate Change, 2013.

[ 2 ] Tian HQ, $\mathrm{Xu} \mathrm{XF,} \mathrm{Lu} \mathrm{CQ} \mathrm{et} \mathrm{al.} \mathrm{Net} \mathrm{exchanges} \mathrm{of} \mathrm{CO}_{2}, \mathrm{CH}_{4}$, and $\mathrm{N}_{2} \mathrm{O}$ between China's terrestrial ecosystems and the atmosphere and their contributions to global climate warming. Journal of Geophysical Research Atmospheres, 2011,116 (G2) : G02011. DOI: 10.1029/2010jg001393.

[ 3 ] Kayranli B, Scholz M, Mustafa A et al. Carbon storage and fluxes within freshwater wetlands: A critical review. Wetlands, 2010, 30(1) : 111-124. DOI : 10.1007/s13157-009-0003-4.

[ 4 ] Xu YK. Effect of vegetation on greenhouse gases emission in estuarine wetland and its response to global change [Dissertation]. Shanghai : East China Normal University, 2017. [许运凯. 河口湿地植被对温室气体排放的影响及其全球变化 响应初探 [学位论文]. 上海: 华东师范大学, 2017.]

[ 5 ] Li YJ. The mechanism of plant effect on greenhouse gas emissions in Yangtze Estuary wetland [Dissertation]. Shanghai: East China Normal University, 2015. [李杨杰. 植被在长江口湿地温室气体排放过程中的影响机制研究 [ 学位论 文]. 上海: 华东师范大学, 2015.]

[6 ] Zhai X, Piwpuan N, Arias CA et al. Can root exudates from emergent wetland plants fuel denitrification in subsurface flow constructed wetland systems? Ecological Engineering, 2013, 61: 555-563. DOI: 10.1016/j.ecoleng.2013.02.014.

[ 7 ] Zhang CB, Wang J, Liu WL et al. Effects of plant diversity on microbial biomass and community metabolic profiles in a full-scale constructed wetland. Ecological Engineering, 2010, 36(1) : 62-68. DOI: 10.1016/j.ecoleng.2009.09.010.

[ 8 ] Zhang CB, Liu WL, Wang $\mathrm{J}$ et al. Effects of monocot and dicot types and species richness in mesocosm constructed wetlands on removal of pollutants from wastewater. Bioresource Technology, 2011, 102(22) : 10260-10265. DOI: 10.1016/j. biortech.2011.08.081.

[ 9 ] Zhu XY. The greenhouse gas emissions from the herbaceous peatland in the Sanjiang Plain and the responses to climate change [Dissertation]. Changchun: Northeast Institute of Geography and Agroecology, Chinese Academy of Sciences, 2015. [ 朱晓艳. 三江平原草本泥炭沼泽温室气体排放及其对气候变化的响应 [学位论文]. 长春: 中国科学院东北 地理与农业生态研究所, 2015.] 
[10] Cao MK, Li KR. Perspective on terrestrial ecosystem-climate interaction. Advance in Earth Sciences, 2000, 15(4): 446452. [ 曹明奎, 李克让. 陆地生态系统与气候相互作用的研究进展. 地球科学进展, 2000, 15(4): 446-452.]

[11] Yin J, Tang YF, Cui HL et al. Emissions of $\mathrm{CO}_{2}$ and $\mathrm{N}_{2} \mathrm{O}$ in sediments with different vegetation types in Chongming Dongtan wetland. Journal of Nanjing Forestry University: Natural Sciences Edition, 2016, 40(4) : 29-34. [ 印杰, 汤逸帆, 崔 洪否等. 崇明东滩湿地不同植物群落下沉积物中 $\mathrm{CO}_{2}$ 和 $\mathrm{N}_{2} \mathrm{O}$ 的释放动态研究. 南京林业大学学报: 自然科学版, 2016, 40(4) : 29-34.]

[12] Baruah KK, Gogoi B, Borah L et al. Plant morphophysiological and anatomical factors associated with nitrous oxide flux from wheat (Triticum aestivum). Journal of Plant Research, 2012, 125 (4) : 507-516. DOI: 10. 1007/s10265-0110464-4.

[13] Gogoi B, Baruah KK. Nitrous oxide emissions from fields with different wheat and rice varieties. Pedosphere, 2012, 22 (1) : 112-121. DOI: 10.1016/s1002-0160(11)60197-5.

[14] Yang GS, Song CC, Wang L et al. Influence of water level gradient on marsh soil microbial activity of Calamagrostis angustifolia. Chinese Journal of Environmental Science, 2010, 31(2) : 444-449. DOI: 10.13227/j.hjkx.2010.02.039. [杨桂 生, 宋长春, 王丽等. 水位梯度对小叶章湿地土壤微生物活性的影响. 环境科学, 2010, 31(2): 444-449.]

[15] Cui M, Caldwell MM. A large ephemeral release of nitrogen upon wetting of dry soil and corresponding root responses in the field. Plant \& Soil, 1997, 191(2) : 291-299.

[16] Manzoni S, Schaeffer SM, Katul G et al. A theoretical analysis of microbial eco-physiological and diffusion limitations to carbon cycling in drying soils. Soil Biology and Biochemistry, 2014, 73: 69-83. DOI: 10.1016/j.soilbio.2014.02.008.

[17] Shi AD, Marschner P. Drying and rewetting frequency influences cumulative respiration and its distribution over time in two soils with contrasting management. Soil Biology and Biochemistry, 2014, 72: 172-179. DOI : 10.1016/j. soilbio.2014. 02.001.

[18] Altor AE, Mitsch WJ. Methane flux from created riparian marshes: Relationship to intermittent versus continuous inundation and emergent macrophytes. Ecological Engineering, 2006, 28(3) : 224-234. DOI : 10.1016/j.ecoleng.2006.06.006.

[19] Mander Ü, Maddison M, Soosaar K et al. The impact of a pulsing water table on wastewater purification and greenhouse gas emission in a horizontal subsurface flow constructed wetland. Ecological Engineering, 2015, 80: 69-78. DOI: 10.1016/j. ecoleng.2014.09.075.

[20] Wang DX. Responses of greenhouse gases emissions from alpine wetland soil to different water level [Dissertation ]. Lanzhou: Gansu Agricultural University, 2015. [王冬雪. 高寒湿地温室气体释放对水位变化的响应 [学位论文]. 兰 州: 甘肃农业大学, 2015.]

[21] Wang JD, Sheng YW, Tong TSD. Monitoring decadal lake dynamics across the Yangtze Basin downstream of Three Gorges Dam. Remote Sensing of Environment, 2014, 152: 251-269. DOI: 10.1016/j.rse.2014.06.004.

[22] Zhou L, Li JB, Tang XM et al. Dynamics of water level of Lake Dongting during the past 60 years and the associated driving factors. Journal of Glaciology and Geocryology, 2017, 39(3): 660-671. [周蕾, 李景保, 汤祥明等. 近 60a 来洞庭 湖水位演变特征及其影响因素. 冰川冻土, 2017, 39(3) : 660-671.]

[23] Shi X. The influence of the river-lake relation change on the Lake Dongting wetland ecology evolution and its regulation [Dissertation]. Shanghai : Donghua University, 2013. [史璇. 江湖关系变化对洞庭湖湖滨湿地生态演变的影响与调 控 [学位论文].上海: 东华大学, 2013.]

[24] Jing L, Lyu C, Zhou Y et al. Spatio-temporal characteristics of the expansion of poplar plantation in West Lake Dongting wetland, China. Chinese Journal of Applied Ecology, 2016, 27 (7) : 2039-2047. DOI: 10.13287/j.1001-9332.201607. 025. [靖否, 吕偲, 周延等. 西洞庭湖湿地杨树人工林扩张的时空特征. 应用生态学报, 2016, 27 ( 7 ) : 2039-2047.]

[25] Li G, Li HL, Yang M et al. Seasonal and diurnal methane and carbon dioxide emissions from the littoral area of the Miyun Reservoir in Beijing, China. Marine and Freshwater Research, 2018, 69(5) : 751. DOI: 10.1071/mf17114.

[26] Sheng XC, Wu M, Shao XX et al. Effects of simulated water levels on diurnal variation in the emission of three greenhouse gases in reed wetlands in summer. Acta Ecologica Sinica, 2016, 36(15) : 4792-4800. DOI: 10.5846/stxb201501120087. [盛宣才, 吴明, 郡学新等. 模拟水位变化对杭州湾芦苇湿地夏季温室气体日通量的影响. 生态学报, 2016, 36 (15) : 4792-4800.]

[27 ] van Oorschot M, van Gaalen N, Maltby E et al. Experimental manipulation of water levels in two French riverine grassland 
soils. Acta Oecologica, 2000, 21 (1) : 49-62. DOI : 10.1016/s1146-609x (00) 00116-8.

[28] Zhou LY, Yin SL, An SQ et al. Spartina alterniflora invasion alters carbon exchange and soil organic carbon in eastern salt marsh of China. CLEAN - Soil, Air, Water, 2015, 43(4) : 569-576. DOI: 10.1002/clen.201300838.

[29] Xu XWH, Zou XQ, Liu JR. Temporal and spatial dynamics of greenhouse gas emissions and its controlling factors in a coastal saline wetland in north Jiangsu. Environmental Science, 2016, 37(6) : 2383-2392. DOI: 10.13227/j.hjkx.2016. 06.049. [许金王豪, 邹欣庆, 刘晶茹. 苏北潮滩温室气体排放的时空变化及影响因素. 环境科学, 2016, 37(6): 2383-2392.]

[30] Xu YK, Wang DQ, Ren MC et al. Effect of vegetation on greenhouse gases emission from Phragmites australis in the Yangtze River estuary in summer and its diel variation. Earth and Environment, 2018, 46(3): 267-273. [许运凯, 王东启, 任名成等. 芦苇植株对湿地温室气体排放的影响及其日变化特征. 地球与环境, 2018，46(3): 267-273.]

[31] Yang M. Processes of greenhouse gases emission from littoral zone [Dissertation]. Beijing: Beijing Forestry University, 2016. [ 杨萌. 消落带温室气体排放机制研究 [学位论文]. 北京: 北京林业大学, 2016.]

[32] Ding WX, Zhang YH, Cai ZC. Impact of permanent inundation on methane emissions from a Spartina alterniflora coastal salt marsh. Atmospheric Environment, 2010, 44(32) : 3894-3900. DOI: 10.1016/j.atmosenv.2010.07.025.

[33] Xu Q, Wu HM, Chen J et al. Advances in the studies on the factors related to the greenhouse gases emission from wetlands. Wetland Science \& Management, 2013, 9(3) : 61-64. [许芹, 吴海明, 陈建等. 湿地温室气体排放影响因素研 究进展. 湿地科学与管理, 2013, 9(3): 61-64.]

[34] Zhang CB, Sun HY, Ge Y et al. Plant species richness enhanced the methane emission in experimental microcosms. Atmospheric Environment, 2012, 62: 180-183. DOI: 10.1016/j.atmosenv.2012.08.034.

[35] Ding W, Cai Z, Tsuruta H. Plant species effects on methane emissions from freshwater marshes. Atmospheric Environment, 2005, 39(18) : 3199-3207. DOI: 10.1016/j.atmosenv.2005.02.022.

[36] Maucieri C, Borin M, Milani $\mathrm{M}$ et al. Plant species effect on $\mathrm{CO}_{2}$ and $\mathrm{CH}_{4}$ emissions from pilot constructed wetlands in Mediterranean area. Ecological Engineering, 2019, 134: 112-117. DOI: 10.1016/j. ecoleng.2019.04.019.

[37] Zhang Y. Effect of vegetation restoration on $\mathrm{N}_{2} \mathrm{O}$ flux and ecological effect in Liaohe estuary Phragmites wetland [Dissertation]. Qingdao: Ocean University of China, 2015. [张颖. 生态修复对辽河口芦苇湿地 $\mathrm{N}_{2} \mathrm{O}$ 通量影响机制及生态效 应的研究 [学位论文]. 青岛: 中国海洋大学, 2015.]

[38] Liu X, Hu HQ, Zhao XK et al. Emissions of $\mathrm{CH}_{4}$ and $\mathrm{N}_{2} \mathrm{O}$ from island forested swamp in Dahinggan mountains. Journal of Natural Resources, 2014, 29(9) : 1565-1575. [刘霞, 胡海清, 赵希宽等. 大兴安岭地区岛状林沼泽 $\mathrm{CH}_{4}$ 和 $\mathrm{N}_{2} \mathrm{O}$ 排 放及其影响因子. 自然资源学报, 2014, 29(9) : 1565-1575.]

[39] Xiang SL. The emission of $\mathrm{N}_{2} \mathrm{O}$ from the Chongming Dongtan wetland under different plants [Dissertation]. Shanghai: East China Normal University, 2009. [向圣兰. 崇明东滩湿地不同植被类型下 $\mathrm{N}_{2} \mathrm{O}$ 排放通量研究 [学位论文]. 上海: 华 东师范大学, 2009.]

[40] Wang HT, Yang XR, Zheng TL. Impact of simulated tide and vegetation on the wetland greenhouse gases fluxes. Acta Scientiae Circumstantiae, 2013, 33(12) : 3376-3385. DOI: 10.13671/j.hjkxxb.2013.12.005. [王海涛, 杨小茹, 郑天凌. 模拟潮汐和植被对湿地温室气体通量的影响研究. 环境科学学报, 2013, 33(12): 3376-3385.]

[41] Kandel TP, Lærke PE, Hoffmann CC et al. Complete annual $\mathrm{CO}_{2}, \mathrm{CH}_{4}$, and $\mathrm{N}_{2} \mathrm{O}$ balance of a temperate riparian wetland 12 years after rewetting. Ecological Engineering, 2019, 127: 527-535. DOI : 10.1016/j.ecoleng.2017.12.019. 